\title{
HOW TO START GENTRIFICATION PROCESS USING INTERFEROMETRIC STACK OF SENTINEL-1
}

\author{
N. Yagmur ${ }^{1, *}$, E. Erten ${ }^{1}$, N. Musaoglu ${ }^{1}$ \\ ${ }^{1}$ Istanbul Technical University, Department of Geomatics Engineering, 34469 Maslak Istanbul, Turkey - (yagmurn, eerten, \\ musaoglune)@itu.edu.tr
}

KEY WORDS: PSI, LiCSBAS, Remote sensing, Land suitability, Gentrification, Sentinel-1, Istanbul

\begin{abstract}
:
In Turkey, gentrification has gained importance in the major cities such as Istanbul because of the rapid urbanization. The establishment of the construction land suitability is one of the main issues raised here. However, it is not easy to start gentrification process in Istanbul where there is a developing transportation and already dense housing. Up-to-date structural health information is then required for an optimum gentrification process. The traditional way of obtaining the structural health conditions on building is generally with the stationary measurements. However, in-situ based information can only provide a small amount of information, and it is impossible to conduct for the entire city. In this context, remotely sensed images, specifically synthetic aperture radar (SAR) ones, can easily provide data to monitor not only ground subsidence but also deformation on the urban sites. The main purpose of the study is to monitor the actual condition of the urbanization on unsuitable and important sites and to guide in determining pioneer areas for gentrification process using freely available remote sensing images, in particular Sentinel-1 SAR images. The potential of these data set will be evaluated with the land suitability map (LSM) produced by The Istanbul Metropolitan Municipality (IMM). In this study, we carried out multi-scale interferometric analysis to understand the spatial relationship between the LSM and the freely available satellite-based measurements for detecting urban sites in danger. The capability and usability of PSI and SBAS methods as a guide before gentrification were investigated using Sentinel-1 data covering 2015 and 2018 years.
\end{abstract}

\section{INTRODUCTION}

With changes in politics and economy, major cities are constantly in a circle of renewal, and gentrification is one of the major renewals. Gentrification is an important type of the transformation and is defined as the improvement of central city neighbourhoods according to socioeconomic conditions (Uzun, 2013; Ding et al., 2016). However, not only economic but also geological and geophysical conditions should be considered in the gentrification process. Especially in cities under the threat of disaster, gentrification is gaining great importance. However, using freely available satellite-based measurements could be a fast way to have an initial idea about the up-to-date land suitability of the entire region.

Istanbul, which is one of the major cities in Turkey, is consistently in the urbanization and gentrification process because of earthquake risk. After the 1999 Marmara earthquake, structures which are vulnerable to earthquake and poorly constructed were taken attention (Goksin and Gibson, 2016). Within this scope, The Istanbul Metropolitan Municipality (IMM) carried out a project that aims to direct all plans, projects and investments, from construction plans to infrastructure, to form the basis of earthquake-safe structures and investments that are sensitive to natural disasters in the microregions. The project was ended in 2010, land suitability and liquefaction risk boundary maps were conducted for two microregions. The land suitability map (LSM) have been produced by means of expensive and labor intensive in-situ based surveys. However, freely available satellite-based measurements could be a fast way to have an initial idea about the land suitability of the entire region.

Among the satellite-based methods, Interferometric Synthetic Aperture Radar (InSAR) has great capability in large-scale ground deformation detecting and monitoring over the past decades and be also used for urban instability (Poncos et al., 2014). There are different methods for monitoring movements using interferometric stack of SAR data. Persistent Scatterer Interferometry (PSI) and Small BAseline Subset (SBAS) methods are the most widely used ones for time series InSAR analysis in different structures and regions. PSI is an effective tool for monitoring deformations at sub-centimeter precision in the rocky and man-made surfaces (Erten and Rossi, 2019, Van der Horst et al., 2018, Crosetto et al. 2016). Instead, SBAS is more suitable for monitoring the deformation of natural surfaces (Chen et al., 2018). However, it can be also used for deformation analysis of man-made structures. Dong et al. (2014) used SBAS method for time series subsidence analysis of Shanghai which has also rapid urbanization. Castellazzi et al. (2016) evaluated deformation on the five major cities of the Mexico using SBAS method. Recently, Dong et al. (2021) fused PSI and SBAS methods for monitoring construction project in China.

In the study area, there are a few studies using InSAR time series stack analysis. Aslan et al. (2018) analysed the ground deformation of Istanbul for the date range of 1992 and 2017 using ERS1/2 and Sentinel-1 data with PSI method and evaluated local deformations of sites having different characteristics like made up ground and skyscraper. Free available SAR data are generally preferred for the large-scale analysis, especially Sentinel-1. Imamoglu et al. (2018) and Halicioglu et al. (2021) evaluated ground deformations of the coastal zones of Golden Horn and new metro line construction project in Istanbul using Sentinel-1 data with only PSI method, respectively.

In this study, these two complementary methods, namely PSI and SBAS, were used for monitoring the urbanization process

*Corresponding Author 
and detecting vulnerable regions between May 2015 and February 2018 in Istanbul using free available Sentinel-1 data. Along with these interferometric results, the LSM were evaluated in order to understand their complementary performances in terms of gentrification process.

Comparative results verified that the interferometric stack images can provide unique prior information about site suitability, which was confirmed by the LSM by the metropolitan municipality. The aim of the study is then not only to present the capability of time series InSAR methods but also to be a guide for how to start gentrification in major cities. Additionally, these two methods were compared according to advantages and limitations.

\section{STUDY AREA}

Istanbul is one of the 81 provinces in Turkey and is located between the Black Sea and Marmara Sea $\left(41^{\circ} \mathrm{N}, 29^{\circ} \mathrm{E}\right)$. It is also of great importance in economic, historical and sociocultural aspects and connects Asia and Europe continents. It is the most populous city in the country and its population has increased by $35 \%$ since 2011, hosting more than 15 million people (TUIK, 2021). This study was conducted in the one of the microregions (covering $~ 509 \mathrm{~km}^{2}$ in the Anatolian side of the Istanbul) defined by the IMM for land suitability analysis, see Fig. 1 .

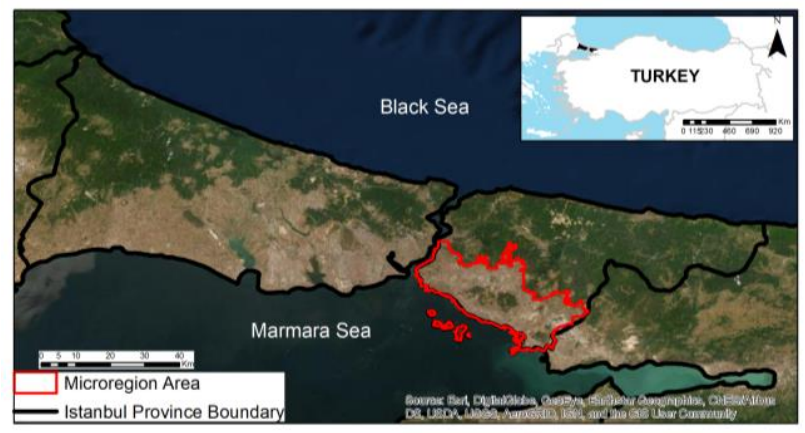

Figure 1. Microregion area located in the Istanbul

In terms of earthquake, Istanbul is the most seismically active and densely populated area in Turkey, containing $15 \%$ of the total risky buildings in Turkey. $68.7 \%$ of the buildings in Istanbul were built before 2000, and 793,800 of these buildings are in danger of collapse (IPA, 2020). 19 districts of Istanbul, 7 of which are on the Anatolian side have been declared as gentrification area (Macin and Demir, 2018). The microregion covers these 7 districts in the Anatolian side. According to the IMM, it is estimated that an average of $17 \%$ of the buildings (approximately 194,000 buildings) in Istanbul will be damaged at medium and above levels, in an earthquake scenario of 7.5 magnitude (IMM, 2019).

\section{DATA USED AND METHODOLOGY}

\subsection{Data Used}

Sentinel-1 SAR images were used for PSI and SBAS experiments in the study. Sentinel-1 images have been provided by European Space Agency (ESA), which supply an in-depth analysis of deformations in urban areas using interferometric methods and are freely available since 2014. The data in the study cover the date range of May 1, 2015 and February 8,
2018. Properties of Sentinel-1 SAR data are given in the Table 1 (Url-1). Temporal resolution of the Sentinel-1 images is regularly 12 days, except Europe including Istanbul. It is acquiring images orbit repeat cycle of 6 days since 2016. Totally 122 images acquired in C band were used in PSI and SBAS processing between May 2015 and February 2018 with ascending geometry. For the study, only VV polarization was considered.

Table 1. Properties of Sentinel-1 images

\begin{tabular}{|l|c|}
\hline \multicolumn{2}{|c|}{ Sentinel-1 (C Band) } \\
\hline Spatial Resolution (m) & 5 (range) $\times 20$ (azimuth) \\
Polarizations & VV, VH \\
Incidence angle $\left({ }^{\circ}\right)$ & $29-46$ \\
Temporal Resolution & 6 days \\
Date Range & $01.05 .2015-08.02 .2018$ \\
\hline
\end{tabular}

The LSMs were generated by the IMM using in-situ survey approach that integrates liquefaction, mass movements, inundation-flood and made-up ground data. These LSMs classify the areas into three groups that are dangerous for dense urbanization: important area (A), important area (B) and unsuitable area. The important area (A) is defined as more vulnerable sites than the important area (B). That is why, unsuitable area and important area (A) classes, covering $0.56 \%$ and $11.70 \%$ of the selected microregion site, respectively, were evaluated (IMM, 2009).

The LSMs were georectified and selected classes were digitized from the georectified map to present current status with created time series deformation maps. The LSM of the microregion is given in Fig. 2.

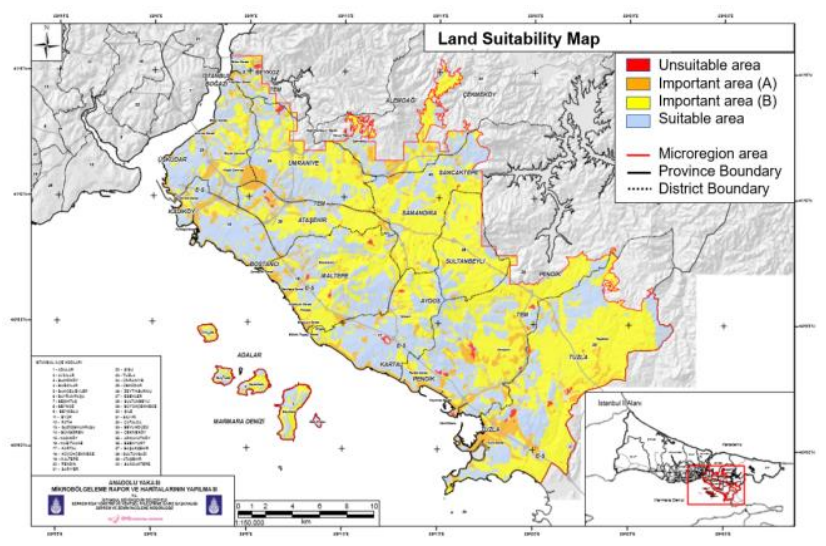

Figure 2. Land suitability map produced by the IMM for the microregion of Anatolian side in Istanbul

\subsection{Methodology}

PSI and SBAS methods were used for the analysis of monitoring deformations in the selected date range on Sentinel1 SAR images. Both of them consider long time series of SAR images. PSI was found by Ferretti et al. (2000) and SBAS method was first implemented by Berardino et al. (2002). PSI time series analysis uses the point targets called persistent scatterers (PS). In PSI processing, firstly differential interferograms were generated according to selected master image and residual height and primary velocity were estimated. Then, atmospheric phase removal was applied and primary velocity was estimated. The final step is geocoding (Erten and Rossi, 2019). PS density is generally low in vegetation, forested 
and low reflectance areas (e.g. very smooth surfaces) and steep terrain surfaces facing radar sensors. Whereas construction sites can cause complete and partial loss of PSs, they are often abundant in buildings, monuments, antennas, poles, conductors, and on top surfaces (Crosetto et al., 2016).

Unlike PSI, SBAS method uses distributed targets and generates small baseline interferograms from all input stack images (Pasquali et al., 2014). To apply SBAS method over the microregion area, LiCSBAS open-source package was used. LiCSBAS is InSAR time series package and applied on the Looking into Continents from Space with Synthetic Aperture Radar (LiCSAR) products which produced InSAR images using Sentinel-1 SAR data. LiCSAR products (wrapped, and unwrapped interferograms and coherence images) are geocoded with nearly $100 \mathrm{~m}$ spatial resolution. That is why, it can be used to find large scale and regional displacements (Morishita et al., 2020; Lazecký et al., 2020). PSI and SBAS results were evaluated with the LSM of the microregion area.

\section{RESULTS AND DISCUSSION}

Fig. 3 shows the number of 372 sites assigned to unsuitable and important area (A) classes in the digitized LSM. In the figure, these classes are grouped according to their land use/land cover (LULC) classes; land, urban and complex. The complex class includes both land and a couple of urban classes. In the study, only urban sites were considered in order to better understand the gentrification process.

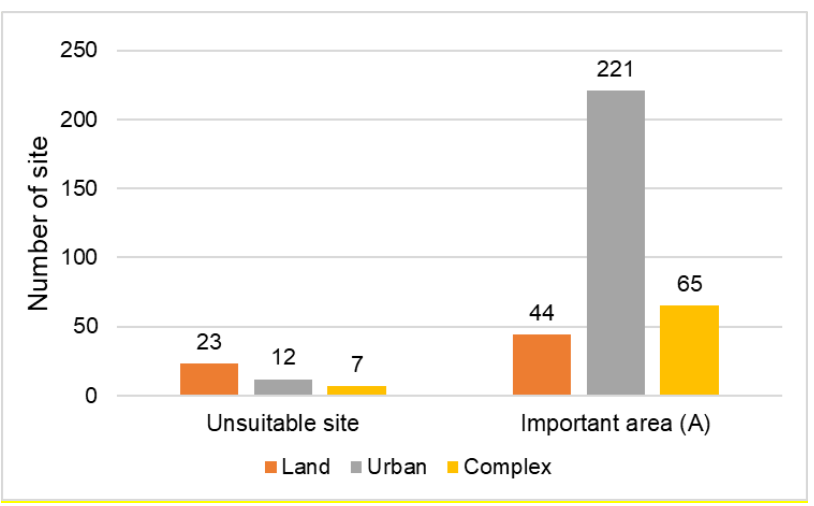

Figure 3. The number of sites assigned to unsuitable and important area (A) classes in the digitized LSM.

PSI and LiCSBAS deformation results were obtained from 122 Sentinel-1 satellite images. The obtained point-based Line of Sight (LOS) deformation velocity results with PSI method were interpolated and resampled to the pixel size of the LiCSBAS deformation results for comparative analysis in the same scale. The results, showing the amplitude of the annual displacement, are given in Fig. 4. There is a difference between PSI and LiCSBAS maps in the north-east side of the study area. The main reason is related to the fact that PSI method is limited to provide measurements over natural surfaces and construction sites. Due to this fact, the interpolation/rasterization process could be avoided if there are not enough PS points.

The 372 sites were overlapped with these interferometric results to compare their sensitivity to the LSM. PSI and LiCSBAS deformation results matched approximately $61.6 \%$ with each other according to these digitized sites.
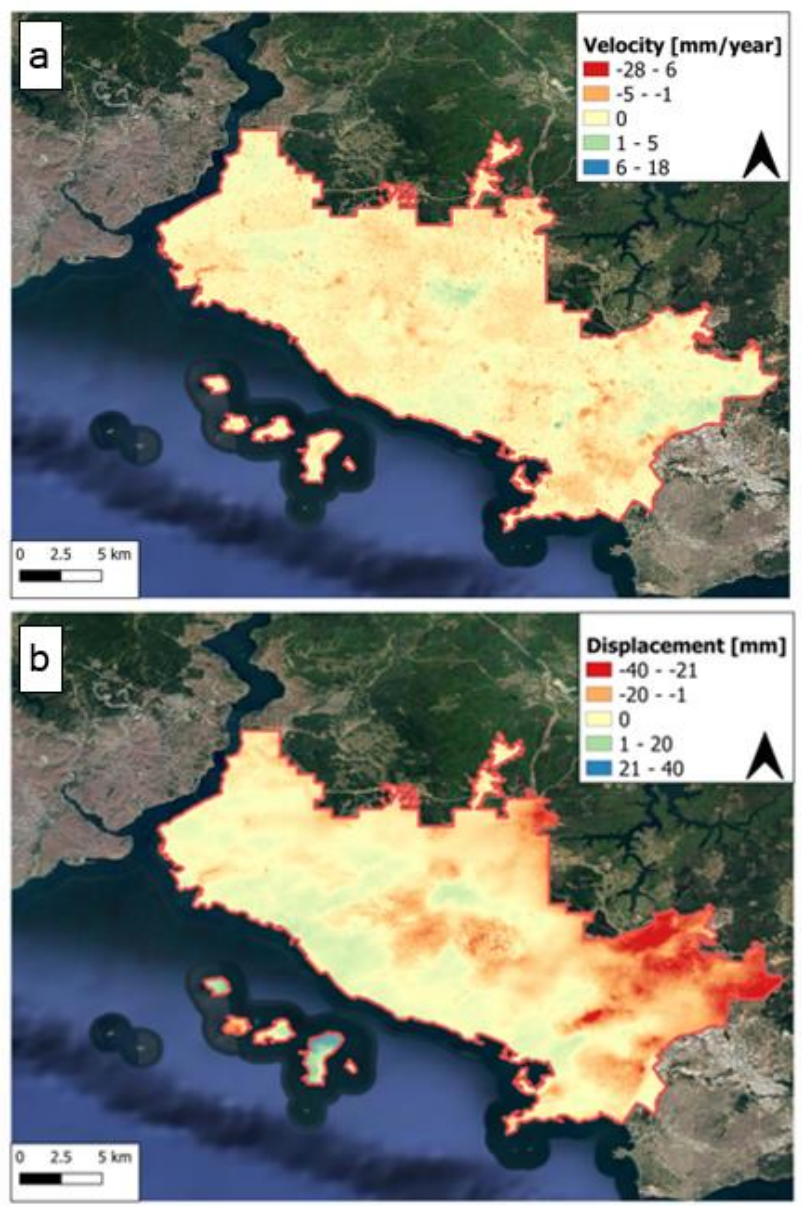

Figure 4. Amplitude of the annual displacement with a) PSI and b) LiCSBAS over the Google Earth satellite image. Note that colour scale is different between (a) and (b).

For starting the gentrification, firstly the current status of urban sites which were determined as unsuitable or important area (A) should be examined. In the unsuitable sites, there are 12 urban areas, and 5 of them were found in danger based on both the PSI and the SBAS methods. As an example, Fig. 5 demonstrates the temporal trend of these measurements over one of the areas defined as in danger. PS points were shown over the Google Earth image in Fig. 5. Dots with different colours indicate the amplitude of the LOS movements. PS points with red colour, which had higher deformation velocity than the other measurement points, were selected to show the PSI time series, and the matched pixels with the red points were shown in the LiCSBAS time series. For the area, the LiCSBAS found lower deformation rate than PSI. Trendlines were given in the linear form. The LOS movement for this site reached nearly $\sim 10 \mathrm{~mm}$ with LiCSBAS, $\sim 70 \mathrm{~mm}$ with PSI. 


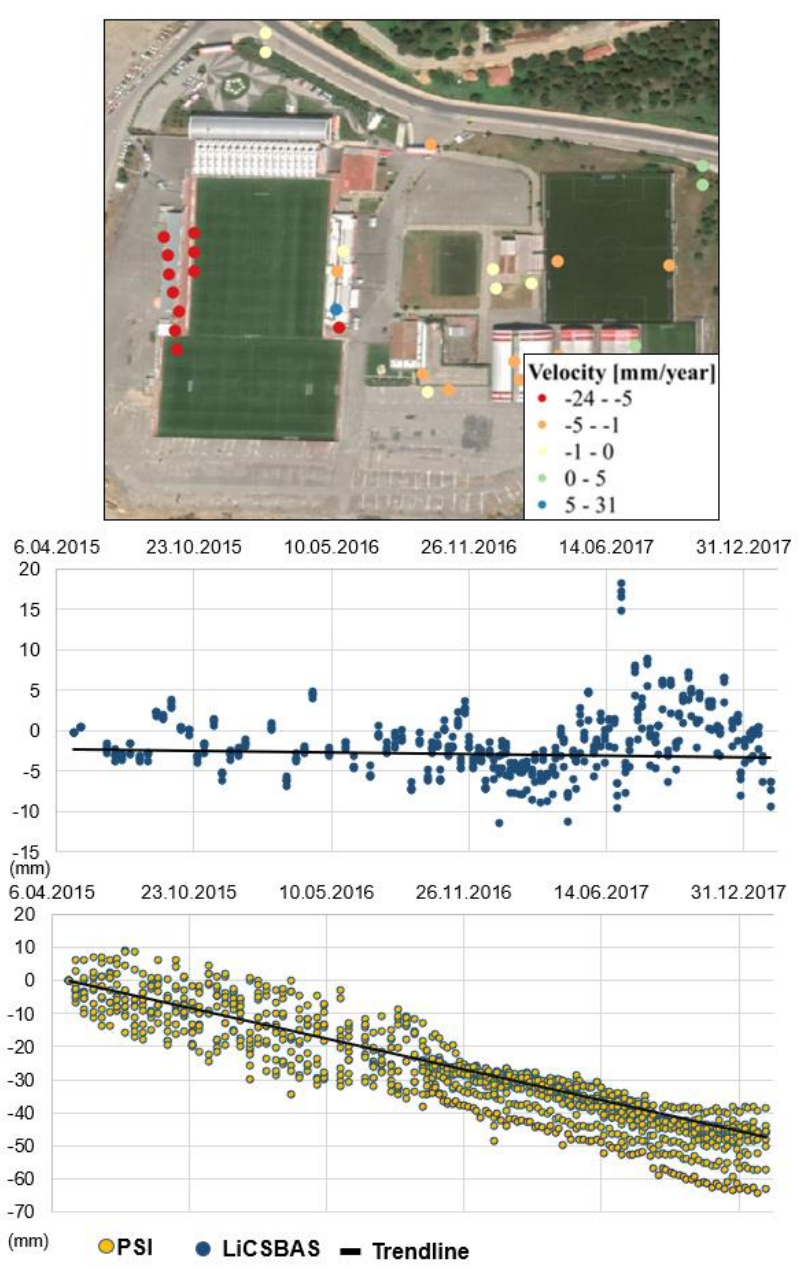

Figure 5. An example for unsuitable site with time series of the PSI and LiCSBAS method. The LOS time series is from the area shown by the red dots.

In the important sites (A), there are 330 sites and 221 of them are located in urban sites. 29 urban sites matched as unsuitable area with both methods. There may be multiple reasons of detected deformation. However, 3 main part of these sites are located in the side of Kadıköy Kurbağalıdere Creek. Additionally, IMM was declared there as a liquefaction risk site (IMM, 2009). As an example, Fig. 6 shows the deformation trend in this region over the Google Earth Image. It can be easily seen that PS points close to the creek have larger deformation rates compared to their surroundings. Both methods showed an increasing subsidence trend for this site. The LOS movement reached approximately $\sim 20 \mathrm{~mm}$ with LiCSBAS, $\sim 35 \mathrm{~mm}$ with PSI method.

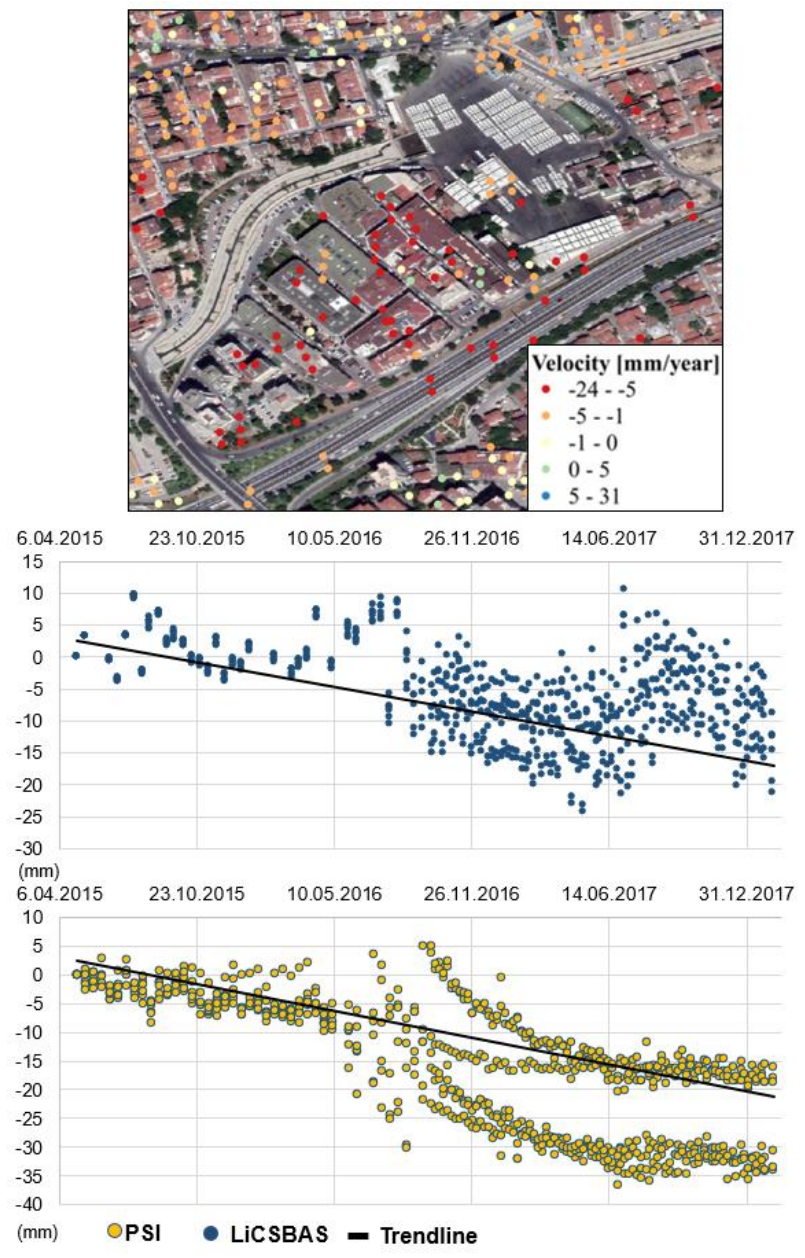

Figure 6. An example for important area (A) with time series of the PSI and LiCSBAS method. The LOS time series is from the area shown by the red dots.

There could be deformation sites which are not located in the important class of the LSM map. There are a lot of contributing factors of subsidence in these sites like groundwater withdrawal, metro lines, highways and rapid urbanization (Dong et al., 2014). In these sites, the main reason of the deformation could be construction sites near to the buildings. The infrastructure constructions like metro stations are generally affected their surroundings. Fig. 7 shows the urban area which did not belong to the unsuitable and important area (A) classes. But there is an ongoing metro construction site which starts in February 2016. For detailed analysis, PSI time series deformation results were given this site in Fig. 7. It is clearly observed that, after the beginning of the metro station construction, deformation velocity showed an increasing subsidence trend (Halicioglu et al., 2021). The area having higher deformation velocity is only the metro station construction site; the surrounding is quite stable. Especially, the urban site opposite to the construction site has red color, highlighting the ground movement. The time series of these red coloured PS points can be seen in Fig. 7. According to the linear trend analysis, the LOS movement is around $\sim 25 \mathrm{~mm}$.

Additionally, sometimes -like the case given in Fig. 7, there are buildings like schools, hospitals, etc. around the construction sites, which have higher importance in the gentrification process than other buildings. For that purpose, detecting deformation around big construction sites are gaining importance, and the 
interferometric techniques could play an important role for providing the ground movement trends in a short time (Dong et al., 2021).

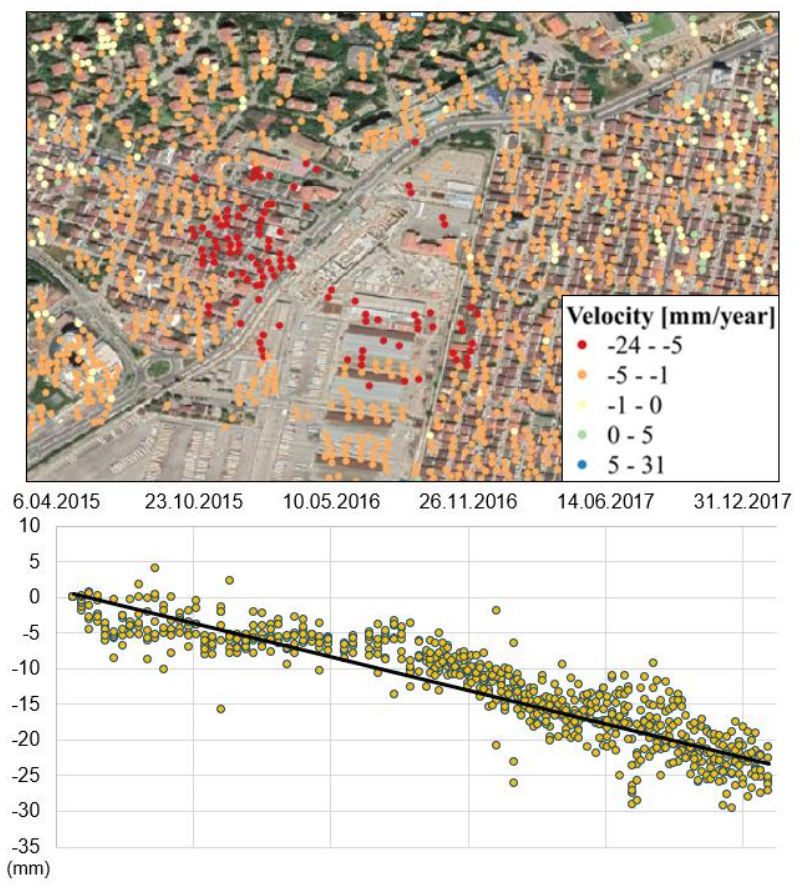

Figure 7. An urban site located near to the new metro station construction, and the time series of red coloured PS points over the Google Earth image.

\section{CONCLUSION}

According to the results, both the PSI and the LiCSBAS methods have huge potential to demonstrate the important areas for starting the gentrification process. Both methods underline how freely available Sentinel-1 data can provide complementary measurements for detecting sensitive areas that could be used for further investigation by the municipality.

In this context, the multi-scale approach could be considered: firstly, with LiCBAS the general terrain subsidence rate of the city can be obtained, and then with PSI methodology, the detailed information on the structural health of the buildings can be reported. Buildings located in not only important site but also around the construction site should be examined in this part.

\section{REFERENCES}

Aslan, G., Cakır, Z., Ergintav, S., Lasserre, C., Renard, F. 2018: Analysis of secular ground motions in Istanbul from a long-term InSAR time-series (1992-2017). Remote Sensing, 10(3), 408. doi.org/10.3390/rs10030408

Berardino, P., Fornaro, G., Lanari, R., Sansosti, E. 2002: A new algorithm for surface deformation monitoring based on small baseline differential SAR interferograms. IEEE Transactions on Geoscience and Remote Sensing, 40(11), 2375-2383. doi.org/10.1109/TGRS.2002.803792

Castellazzi, P., Arroyo-Domínguez, N., Martel, R., Calderhead, A. I., Normand, J. C., Gárfias, J., Rivera, A., 2016: Land subsidence in major cities of Central Mexico: Interpreting
InSAR-derived land subsidence mapping with hydrogeological data. International Journal of Applied Earth Observation and Geoinformation, 47 ,

102-111. doi.org/10.1016/j.jag.2015.12.002

Chen, H., Yang, T., Wang, Y., Yan, Y., 2018: Assessing deformation of and impact of earthquakes on JiuzhaiHuanglong Airport, China with InSAR Techniques. In EUSAR 2018; 12th European Conference on Synthetic Aperture Radar 1-4. VDE.

Crosetto, M., Monserrat, O., Cuevas-González, M., Devanthéry, N., Crippa, B., 2016: Persistent scatterer interferometry: A review. ISPRS Journal of Photogrammetry and Remote Sensing, 115, 78-89. doi.org/10.1016/j.isprsjprs.2015.10.011

Ding, L., Hwang, J., Divringi, E., 2016: Gentrification and residential mobility in Philadelphia. Regional Science and Urban Economics, 61, 38-51. doi.org/10.1016/j.regsciurbeco.2016.09.004

Dong, J., Lai, S., Wang, N., Wang, Y., Zhang, L., \& Liao, M. (2021). Multi-scale deformation monitoring with Sentinel-1 InSAR analyses along the Middle Route of the South-North Water Diversion Project in China. International Journal of Applied Earth Observation and Geoinformation, 100, 102324. doi.org/10.1016/j.jag.2021.102324

Dong, S., Samsonov, S., Yin, H., Ye, S., Cao, Y. 2014: Timeseries analysis of subsidence associated with rapid urbanization in Shanghai, China measured with SBAS InSAR method. Environmental Earth Sciences, 72(3), 677-691. doi.org/10.1007/s12665-013-2990-y

Erten, E., Rossi, C., 2019: The worsening impacts of land reclamation assessed with Sentinel-1: The Rize (Turkey) test case. International Journal of Applied Earth Observation and Geoinformation, 74, 57-64. doi.org/10.1016/j.jag.2018.08.007

Ferretti, A., Prati, C., Rocca, F., 2000: Nonlinear subsidence rate estimation using permanent scatterers in differential SAR interferometry, IEEE Transactions on Geoscience and Remote Sensing, 38(5), 2202-2212.

Goksin, Z. A., Gibson, M., 2016: Neighbourhood Regeneration in Istanbul: from Earthquake Mitigation to Planned Displacement and Gentrification. In Carola Hein (ed.) International Planning History Society Proceedings, 17th IPHS Conference, History-Urbanism-Resilience, TU Delft, 02, 283. doi.org/10.7480/iphs.2016.2.1243

Halicioglu, K., Erten, E., Rossi, C., 2021: Monitoring Deformations of Istanbul metro line stations through Sentinel-1 and levelling observations. Environmental Earth Sciences, 80, 361. doi.org/10.1007/s12665-021-09644-0

Imamoglu, M., Kahraman, F., Abdikan, S., 2018: Preliminary results of temporal deformation analysis in Istanbul using multitemporal InSAR with Sentinel-1 SAR data. In IEEE International Geoscience and Remote Sensing Symposium $\begin{array}{lll}\text { (IGARSS 2018), } & \text { 1352-1355. }\end{array}$ doi.org/10.1109/IGARSS.2018.8518755

IMM (Istanbul Metropolitan Municipality), 2009: Istanbul Microregion Project Anatolian Side. Retrieved from: 
https://depremzemin.ibb.istanbul/calismalarimiz/tamamlanmiscalismalar/istanbul-ili-mikrobolgeleme-projeleri/. (in Turkish)

IMM (Istanbul Metropolitan Municipality), 2019: Istanbul Province Probable Earthquake Loss Estimation Update Project. Retrieved from: https://depremzemin.ibb.istanbul/calismalarimiz/tamamlanmiscalismalar/istanbul-ili-olasi-deprem-kayip-tahminlerininguncellenmesi-projesi/. (in Turkish)

IPA (Istanbul Planning Agency), 2020: Istanbul Urban Analysis Report, Retrieved from: https://vizyon2050.istanbul/yayindetay1-14-istanbul_kentsel_analiz_raporu. (in Turkish)

Lazecký, M., Spaans, K., González, P. J., Maghsoudi, Y., Morishita, Y., Albino, F., ... Wright, T. J., 2020: LiCSAR: An automatic InSAR tool for measuring and monitoring tectonic and volcanic activity. Remote Sensing, 12(15), 2430. doi.org/10.3390/rs12152430

Macin, K. E., Demir, İ., 2018: Kentsel dönüşüm sürecinde İstanbul'da inşaat ve yıkıntı atıkları yönetimi. Adıyaman Üniversitesi Mühendislik Bilimleri Dergisi, 5(9), 188-201. (in Turkish)

Morishita, Y., Lazecky, M., Wright, T. J., Weiss, J. R., Elliott, J. R., \& Hooper, A., 2020: LiCSBAS: An open-source InSAR time series analysis package integrated with the LiCSAR automated Sentinel-1 InSAR processor. Remote Sensing, 12(3), 424. doi.org/10.3390/rs12030424

Pasquali, P., Cantone, A., Riccardi, P., Defilippi, M., Ogushi, F., Gagliano, S., Tamura, M., 2014: Mapping of ground deformations with interferometric stacking techniques. Land Applications of Radar Remote Sensing, 233-259. doi.org/10.5772/58225

Poncos, V., Teleaga, D., Boukhemacha, M. A., Toma, S. A., Serban, F., 2014: Study of urban instability phenomena in Bucharest city based on Ps-InSAR. In 2014 IEEE Geoscience and Remote Sensing Symposium, 429-432. IEEE. doi.org/10.1109/IGARSS.2014.6946450

TUIK, 2021. http://www.tuik.gov.tr/

Url-1: https://sentinel.esa.int/web/sentinel/user-guides/sentinel1-sar/resolutions/level-1-single-look-complex

Uzun N., 2013: Urban Space and Gentrification in Istanbul in the Twentieth Century. The Economies of Urban Diversity. Palgrave Macmillan, New York, 235-254. doi.org/10.1057/9781137338815_11

Van der Horst, T., Rutten, M. M., Van de Giesen, N. C., Hanssen, R. F., 2018: Monitoring land subsidence in Yangon, Myanmar using Sentinel-1 persistent scatterer interferometry and assessment of driving mechanisms. Remote Sensing of Environment, 217, 101-110. doi.org/10.1016/j.rse.2018.08.004 